\title{
Urdimento
}

Revista de Estudos em Artes Cênicas

E-ISSN: 2358.6958

\section{Stanislávski: sem censura nem cortes}

\author{
Sharon Marie Carnicke
}

Tradução: Felipe Rodrigues Carvalho

\section{Para citar este artigo:}

CARNICKE, Sharon M. Stanislávski: sem censura nem cortes. Trad. Felipe Carvalho. Urdimento, Florianópolis, v. 1, n. 40, mar./abr. 2021.

do) DOI: http:/dx.doi.org/10.5965/1414573101402021e0700 
Stanislávski: sem censura nem cortes

Sharon Marie Carnicke ${ }^{1}$

Tradução: Felipe Rodrigues Carvalho²

\begin{abstract}
Resumo
O artigo traça um panorama histórico e biográfico das últimas décadas de vida de Constantin Stanislávski para compreender em que medida sua imagem e a sua obra foram construídas, manipuladas e até modificadas, dentro e fora da Rússia. A professora Sharon Marie Carnicke resgata as complexidades e contradições às quais Stanislávski esteve submetido tanto na Rússia, frente ao regime de censura e propaganda materialista-dialética de Stalin, quanto nos Estados Unidos, através das turnês do Teatro de Arte de Moscou que promoveram o diretor no Ocidente mas, sobretudo, através do decisivo contrato editorial assinado com sua tradutora Elizabeth Hapgood.
\end{abstract}

Palavras-chaves: Constantin Stanislávski. Processo editorial. História do teatro.

\title{
Stanislavsky: Uncensored and Unabridged
}

\begin{abstract}
The paper traces a historical and biographical panorama of Konstantin Stanislavsky's last decades of life to understand to what extent his image and work were framed, manipulated, and even modified, inside and outside Russia. Professor Sharon Marie Carnicke recalls the complexities and contradictions to which Stanislavsky was subordinated both in Russia in the face of Stalin's censorship and materialisticdialectic propaganda and in the US, either through the tours of the Moscow Art Theater that boosted the director in the West, or through the crucial copyright contract signed with his translator Elizabeth Hapgood.
\end{abstract}

Keywords: Konstantin Stanislavsky. Publishing process. Theater History.

${ }^{1}$ Professora de teatro e línguas e literaturas eslavas e uma das fundadoras do Centro de Excelência em Ensino da USC. Fluente em russo, ela é a autora internacionalmente aclamada de Stanislávski in Focus (agora em sua segunda edição), que revela as maneiras significativas nas quais o Método Americano e o Sistema Stanislávski de treinamento de atores diferem um do outro. As críticas consideram seu livro leitura essencial para atores, diretores e acadêmicos de teatro. PhD, Columbia University - USA. carnicke@usc.edu

${ }^{2}$ Ator e bacharelando em Artes Cênicas com habilitação em Interpretação Teatral pela Escola de Comunicações e Artes da Universidade de São Paulo (ECA-USP). Fez intercâmbio de graduação pela Université Paris 8 VincennesSaint-Denis (França), onde estudou teatro durante o ano letivo de 2019/2020. Atua como tradutor para o português de textos e artigos em línguas inglesa e francesa. felipe.r.carvalho96@gmail.com

(2) http://lattes.cnpq.br/7652040518740919 (iD https://orcid.org/0000-0002-6104-925X 
Stanislavski: sin censura e íntegro

\section{Resumen}

Ese artículo traza un panorama histórico y biográfico de los últimos años de vida de Konstantín Stanislavski para comprender hasta qué punto su imagen y obra fueron enmarcadas, manipuladas e incluso modificadas, dentro y fuera de Rusia. La profesora Sharon Marie Carnicke recuerda las complejidades y contradicciones a las que fue sometido Stanislavski tanto en Rusia, ante el régimen de censura y propaganda materialista-dialéctica de Stalin, como en Estados Unidos, ya sea a través de las giras del Teatro de Arte de Moscú que impulsó al director en Occidente, o mediante el crucial contrato editorial de sus obras firmado con su traductora Elizabeth Hapgood.

Palabras clave: Konstantín Stanislavski. Proceso editorial. Historia del teatro. 


\section{Sobre a autora}

Mundialmente aclamada estudiosa em Stanislávski, Sharon Marie Carnicke é um expoente ímpar nos estudos de teatro eslavo, combinando atuação na área com a fluência na língua e cultura russas. Começou como atriz e dançarina, apaixonando-se pelos clássicos nos festivais promovidos pelo American Shakespeare Theatre, em Stratford (Connecticut, EUA), onde cresceu, e estreou na direção ao ser cofundadora do Potato Players, um coletivo de teatro de Nova York, dedicado a peças novas. Stanislávski adentrou em sua vida quando ela foi estudar Literatura Russa, na Barnard College, obteve doutorado em russo, na Columbia University e, então, viajou muito pela Rússia onde, ao longo dos anos, estudou Stanislavsky através de seus ex-alunos e de seus escritos não publicados, consultados nos arquivos do Teatro de Arte de Moscou. Como autora, ela é mais conhecida por seu livro Stanislavsky in Focus (Routledge), que atravessa os mitos persistentes e incorretos sobre o homem e seu Sistema, elucidando a história. Dentre suas inúmeras publicações, há estudos inovadores sobre atuação para câmera, como Reframing Screen Performance (coautora). Publicou, também, bastante sobre Anton Tchékhov, tendo sido premiada com a tradução de suas peças na antologia Four Plays and Three Jokes. Professora e diretora experiente, Sharon é uma defensora apaixonada da Análise-Ação, técnica de ensaio tardia de Constantin Stanislávski, que ela já ensinou em vários cantos do mundo, como Porto Rico, Noruega, Austrália, Finlândia, Inglaterra, Itália e França. Tendo lecionado anteriormente na Universidade de Nova York, atualmente, ela é professora de Teatro e Línguas e Literaturas Eslavas da Universidade da Califórnia do Sul.

\section{Nota do tradutor}

O artigo foi inicialmente publicado pela MIT Press na revista The Drama Review, v. 37, n. 1, mar./maio, 1993. Posteriormente, foi publicado na antologia 
organizada por Gabrielle Cody e Rebecca Schneider, Re-Direction: A Theoretical and Practical Guide, New York: Routledge, 2001. Nessa reimpressão o texto foi reduzido pelo conselho editorial e teve partes removidas pela autora, a fim de atualizar as referências sobre certas edições publicadas e traduzidas de Stanislávski. Com o consentimento de Sharon M. Carnicke, a presente tradução contém trechos da edição de 1993 que foram removidos da reimpressão de 2001, mantendo desta última, apenas os cortes, feitos pela autora, dos trechos que diziam respeito à situação editorial de obras citadas - o que fazia sentido, à época da primeira publicação, em 1993. Assim, atualizada para os dias de hoje, a presente tradução compõe uma edição única até para a língua inglesa, pois além de atualizada bibliograficamente frente à primeira edição, não contém os cortes editoriais da segunda.

* As notas da autora aparecem com a marcação (NA), as do tradutor com (NT). Todos os comentários, entre colchetes, que estiverem dentro de uma citação, seja em notas, seja no corpo do texto, são marcações da própria autora.

**Como o artigo trata da problemática das traduções, os títulos, das obras de Stanislávski publicadas em inglês, aparecerão referenciados como no original, apenas com uma tradução, em nota ou entre colchetes, durante cada uma de suas primeiras aparições no texto. 


\section{Stanislávski: sem censura nem cortes $^{3}$}

Pronuncie o nome Stanislávski e você invoca imagens míticas: um professor aparentando um vovô com seu pince-neż, que revela os segredos da grande atuação a jovens e inseguros alunos, um disciplinador rigoroso que exige comprometimento total à arte, um grande diretor realista que explora as verdades enraizadas nas peças e nas almas dos atores. A força desses mitos nos Estados Unidos não se resume apenas aos círculos teatrais, mas também à cultura popular. Plateias não precisam estudar teatro para entender a piada central em Que sorte danada. . um filme em que Shelley Long e Bette Midler competem por vagas em uma aula de atuação lecionada por um homem com um misterioso sotaque do leste europeu, cujo nome suspeitamente se parece com o de Stanislávski (Dixon, 1987). Essa é a nossa primeira imagem do professor de atuação. Tampouco se perdem as referências ao Método em Tootsie ${ }^{6}$, de maior público. Nesse filme, Dustin Hoffman, ele próprio um membro do Actors Studio, interpreta um ator que é demitido por, meticulosamente, porém de forma inapropriada, aplicar o Método em seu trabalho (Gelbard e Schisgal, 1982)7.

Embora alimentadas por um contexto cultural diferente, imagens semelhantes do grandioso diretor realista e professor de interpretação surpreendentemente se desenvolveram na União Soviética. Por volta da década de 1930, manchetes de jornais soviéticos anunciavam Stanislávski com louvor mítico. Ele foi "nosso orgulho" (Yura, 1938, p. 412), "o Gênio do Teatro" (Derman, 1938), "o Criador do Teatro Realista" (Khailov, 1938), esteve na linha de frente da

${ }^{3}$ (NT) CARNICKE, Sharon M. Stanislavsky: Uncensored and Unabridged, The Drama Review, v. 37, n. 1, Spring, 1993, p. 22-37.

${ }^{4}$ (NT) No original em francês, pince-nez, literalmente "pinça-nariz", é um tipo de óculos sem hastes que se fixa ao nariz por meio de uma mola.

${ }^{5}$ (NT) Filme norte-americano de 1987, Outrageous Fortune foi dirigido por Arthur Hiller e lançado em português sob o título "Que sorte danada!"

${ }^{6}$ (NT) Filme norte-americano de 1982, dirigido por Sydney Pollack.

(NA) Nomes russos foram anglicizados neste texto. As referências bibliográficas no fim do artigo estão transliteradas de acordo com o sistema da Biblioteca do Congresso [Washington, EUA]. Todas as traduções de fontes russas são minhas a menos que haja alguma nota. 
"Batalha pelo Realismo" (Gus, 1938) como uma "Tribuna da Verdade Cênica" (Grigor'ev, 1938).

As circunstâncias comerciais, políticas e sociais que, com tanto êxito, nutriram esses mitos também tornam difícil encontrar o homem por trás da imagem. Na teoria, se espera que os livros de Stanislávski sirvam como um corretivo às distorções míticas. Não poderíamos simplesmente checar nossos conhecimentos sobre ele a partir dos seus registros escritos? Mesmo que, na maioria dos casos, essa abordagem seja normal e acadêmica, no caso de Stanislávski seus livros levantam uma nova gama de questões. Até agora, seus escritos foram publicados em versões modificadas que apresentam visões, no melhor dos casos, parciais e, no pior deles, distorcidas de suas ideias. As mesmas circunstâncias, que se provaram solo fértil para a criação de mitos, impediram o acesso às informações escritas.

Na União Soviética, a censura e a eliminação de textos que iam de encontro às normas do partido oficial, encorajaram um retrato modificado e retocado do artista. Stanislávski corajosamente lutou contra essas incursões em seus livros e, em grande medida, obteve significativas vitórias. Por isso, a corrente edição de seus Collected Works (1954-1961) [Trabalhos Reunidos], mesmo satisfazendo, em certa medida, a linha do partido, ainda representou a melhor fonte de informação escrita. Essa edição nunca encontrou uma versão em língua inglesa.

Nos Estados Unidos, editoras comerciais rejeitaram as explicações sutis e complexas sobre a natureza experimental da interpretação teatral em prol de livros que fossem consideravelmente mais comerciáveis, assegurando que os manuscritos aparecessem em versões muito resumidas e modificadas. An Actor Prepares $^{8}$, por exemplo, foi aceito para publicação somente com a condição de que fosse reduzido e de que todas as referências obscuras demais para um leitor estadunidense fossem removidas. Nos Estados Unidos, Stanislávski concordou

\footnotetext{
${ }^{8}$ (NT) An Actor Prepares (1936) foi traduzido do russo por Elizabeth Reynolds Hapgood. Essa versão em língua inglesa foi, então, retraduzida para o português, por Pontes de Paula Lima sob o título de $A$ preparação do ator e publicada pela editora Civilização Brasileira (Rio de Janeiro), em 1964. Há também uma versão portuguesa, igualmente traduzida desta versão em inglês, sob o título de A Preparação do Actor, publicada pela, à época, editora Arcádia (Lisboa), em 1962, e reeditada sob coordenação de Ângela Correia, em 2016, pela Bibliotrónica Portuguesa (Lisboa).
} 
com as demandas comerciais, em parte, porque ele precisava desesperadamente de dinheiro e, em parte, porque ele não sabia ler inglês. Sendo assim, na maioria dos casos as versões de seus textos em língua inglesa variam significativamente dos livros russos.

Além disso, sob pressões da publicação, o próprio Stanislávski complicou a situação. Ele estava constantemente desenvolvendo suas teorias, nunca satisfeito, nem mesmo com as respostas que ele havia encontrado para a maioria das suas questões básicas. Ele ponderava cada palavra, revisando e reformulando cada página inúmeras vezes, Stanislávski concebia tudo o que escrevia como "anotações de trabalho para atores"'. Ele deixou para trás extensos rascunhos incompletos, passagens alternadas e infinitas revisões, revelando em cada página de seus manuscritos e datilografias o seu torturante e obsessivo trabalho. Desesperado em cumprir com prazos editoriais, ele dependeu de uma série de editores para terminar seus livros, incluindo Aleksandr Koiransky, um emigrado russo; Lyubov Gurevich, uma amiga próxima; Norman e Elizabeth Reynolds Hapgood, dois cidadãos norte-americanos com os quais ele fez amizade em suas turnês; e seu aluno Grigory Kristi. Esses editores tiveram um papel importante em remodelar e, em parte, construir as teorias de Stanislávski. O trabalho deles precisa ser desembaraçado a fim de melhor compreender o que dos textos é fidedigno a Stanislávski. Resumindo, enquanto achávamos que conhecíamos Stanislávski, na verdade, ainda não vimos o que ele, de fato, escreveu sem censura nem cortes.

Entramos agora em uma nova era dos estudos stanislávskianos, que questiona as fortes imagens míticas que se desenvolveram na década de 1930. Durante os últimos anos, em encontros internacionais em Moscou, Paris, Cambridge (Massachusetts) e Louisville (Kentucky) ${ }^{10}$, acadêmicos e profissionais do

\footnotetext{
9 (NA) Partiu de uma discussão com Inna Solovyona, professora do Estúdio-Escola do Teatro de Arte de Moscou e da Academia Russa de Artes Teatrais (antiga GITIS); ver também (Benedetti, 1990, p. 317).

10 (NA) "Stanislávski in a Changing World" [Stanislávski num mundo em mudança], "International Center for Stanislavsky Studies" [Centro Internacional de estudos em Stanislávski], 1989; "Symposium on the Translation of Stanislavsky" [Simpósio sobre a Tradução de Stanislávski], Teatro de Arte de Moscou, Moscou, 1990; "Le Siècle Stanislávski" [O século Stanislávski], Centro Georges Pompidou, Paris, 1988; "Colloquium on Stanislavsky" [Colóquio sobre Stanislávski], Palais de Chaillot, Paris, 1991; "Russian Emigré Drama” [Drama russo emigrado], Universidade de Harvard, Cambridge (Massachusetts), 1991; "Russian Classics in Context" [Clássicos Russos em Contexto], Actors Theater of Louisville, Louisville (Kentucky), 1989.
} 
teatro, igualmente, começaram a examinar vários dos pressupostos já estabelecidos sobre quem foi Stanislávski e o que ele ensinou. Grande parte dessa extraordinária atividade começou a desmistificar o homem e o artista, retomandoo novamente ao mundo dinâmico e imperfeito da prática teatral. Esse projeto, entretanto, precisa de novas fontes de informação para prosseguir. Em Moscou, enquanto se debatia sobre a necessidade do Centro para Estudos em Stanislávski [Center for Stanislavsky Studies], representantes de cada canto do mundo frisaram a urgência por informações exatas.

Como se estivessem respondendo a isso, novas edições não-censuradas e sem cortes dos Trabalhos Reunidos de Constantin Stanislávski foram publicadas em russo (pela editora líder em publicações sobre as artes cênicas, Iskusstvo). ${ }^{11}$ Os volumes russos não só republicam os já canônicos escritos de Stanislávski, mas também mostram variantes que revelam o trabalho dos editores em relação aos rascunhos com orientações de procedimentos do autor. Integrando inúmeros arquivos escondidos no Teatro de Arte de Moscou, a edição russa também inclui manuscritos e cartas, os quais nunca se teve a intenção de publicar, intocados pelos mesmos fatores que modificaram os livros publicados. A principal vantagem da edição russa é que a publicação de novos materiais mudará não apenas o nosso entendimento dos fatos biográficos da vida de Stanislávski durante os anos de Stalin, mas também nos dará novos olhares sobre os processos de reflexão pelos quais o famoso Sistema de Stanislávski se desenvolveu.

Para entender quão revolucionárias as novas fontes são e o quanto elas auxiliarão a elucidar aqueles aspectos do trabalho de Stanislávski que vão de encontro aos nossos mitos comuns, precisamos primeiro examinar as “circunstâncias dadas”12 que originalmente criaram fontes primárias errôneas.

\footnotetext{
${ }^{11}$ (NA) A edição Russa, Sobranie sochinenii, começou a aparecer em 1988. Em 1995, inúmeros livros já haviam sido publicados, incluindo uma coleção de dois volumes dos cadernos artísticos de Stanislávski.

Todas as subsequentes referências aos volumes publicados da edição russa aparecerão em notas de rodapé com a sigla "SS" (Sobranie sochinenii) seguida do ano de publicação e do número do volume.

12 (NA) Eu tomo a expressão "circunstâncias dadas" emprestada da história documental sobre a criação de Rabota aketera nad soboi (An Actor Works on Himself) de Vladimir Dybovskii, V Plenu predlagaemyx obstoiatel'stv que ele compartilhou comigo, de forma datilografada.
} 
As circunstâncias forjadoras do retrato de Stanislávski como um Deus teatral do Realismo na URSS traçam uma única, no entanto trágica, trajetória. Na antiga União das Repúblicas Socialistas Soviéticas, a censura e o aumento do controle governamental sobre as artes culminaram no estabelecimento do Realismo Socialista. Em 1934, quatro anos antes da morte de Stanislávski, todos os escritores estiveram juntos em uma única união e foram forçados a adotar um estilo único. O Realismo Socialista destinou-se a fazer com que as artes fossem amplamente acessíveis a uma vasta população sem instrução e a retratar uma realidade idealizada que enxergasse a implantação do comunismo como o destino lógico e teleológico da história. O mesmo colunista de jornal que reverenciou Stanislávski por sua "batalha” pelo Realismo também relembrou seus leitores de que o "Realismo não pode ser genuíno, profundo ou lógico se ele visa a uma ideia falsa, se ele visa ir contra as tendências históricas do desenvolvimento social" (Gus, 1938, p. 3-4). Essa interpretação do que é real causou um particular desgosto aos dramaturgos. Por volta da década de 1940, bezkonfliktnost (ausência de conflito central) foi promovido como uma fórmula necessária para o drama. Em oposição direta às mais profundamente arraigadas tradições dramáticas, foi dito aos escritores que o conflito não era bom para o drama. Afinal de contas, se alguém vivesse no melhor dos mundos possíveis, os únicos conflitos reais que existiriam estariam entre almejar algo "melhor" do que se tem ou almejar o melhor que se pode haver, o "ideal". 13 Tais ideias debilitaram o drama soviético. Teatros enfrentando crises em seus repertórios, buscaram desesperadamente por peças interessantes, mas encontraram medíocres peças "comerciais"14, como o próprio Stanislávski as rotulou (Benedetti, 1990a, p. 322).

13 (NT) Transcrevo o original para esmiuçar um nó linguístico da tradução: After all, if one lives in the best of all possible worlds, the only real conflits that exist are those between 'better' and 'best'. Tanto better quanto best, em português, assumem a mesma forma: "melhor"; de modo que o grau do adjetivo é diferenciado pelo contexto em que é empregado, flexionado ora como comparativo (um mundo melhorla better world), ora como superlativo (o melhor mundo/the best world). Optei por reconstruir a frase em outra estrutura, para não repetir a palavra "melhor" e, também, optei por empregar palavras diferentes ("melhor" e "ideal"), para manter a dicotomia (better-best) que a autora trouxe.

14 (NT) No original potboiler, literalmente "que faz ferver a panela" ou "aquilo que faz a panela ferver", é uma curiosa expressão figurativa e pejorativa que não existe em português. Optei por "comercial", pois potboiler ou pot-boiler designa especificamente uma obra de arte produzida apenas para fins lucrativos, de mérito duvidoso e baixa qualidade, geralmente feita de forma rápida, pela urgente necessidade de sua venda. A panela (pot) é caracterizada pela qualidade da ação de ferver, isto é, "que faz ferver" (boiler), e aquilo que é 
Figura 1 - Arquivos há muito escondidos no Teatro de Arte de Moscou foram abertos, dando acesso a novos rascunhos de manuscritos de Stanislávski

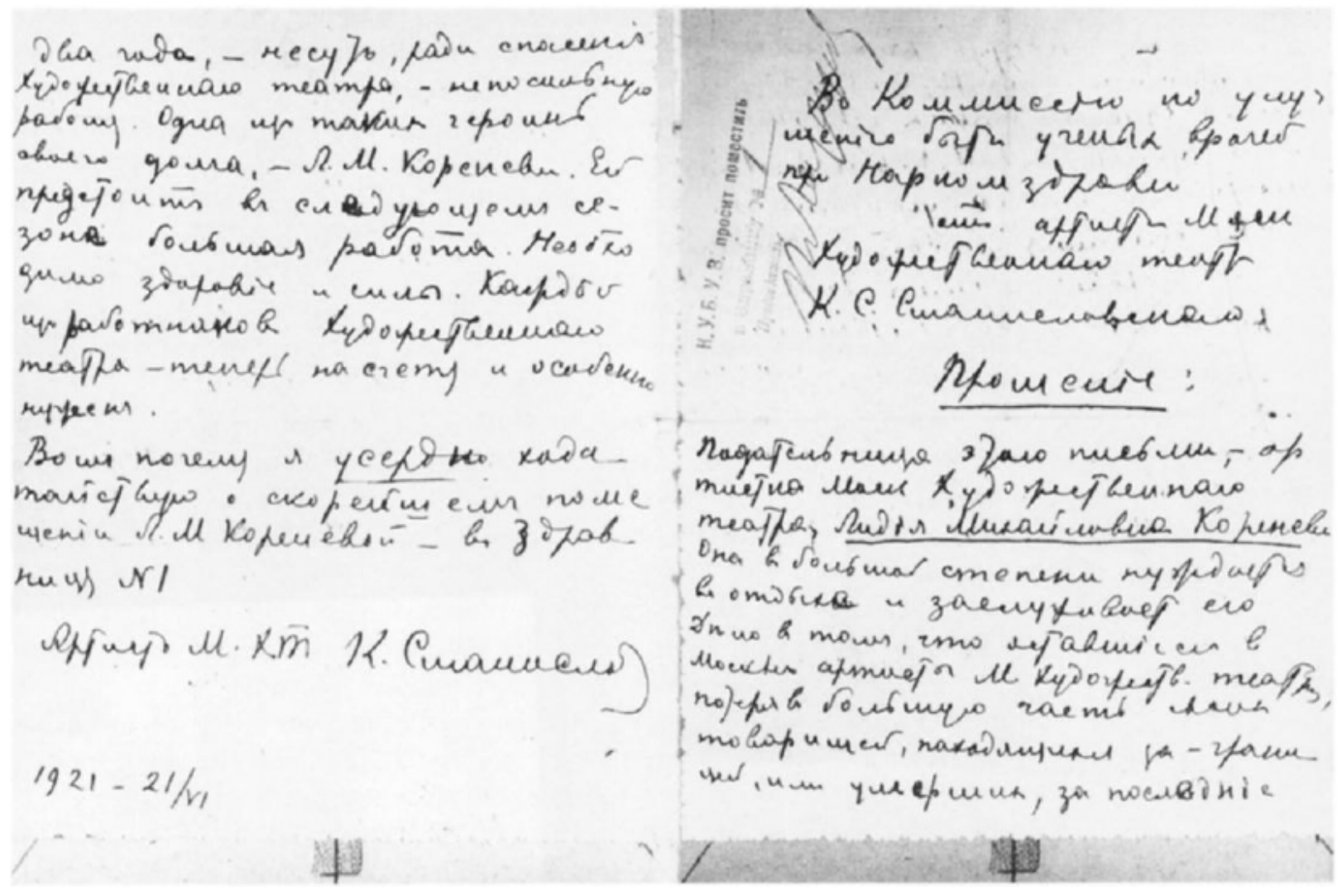

Imagem: Cortesia dos Arquivos de K. S. Stanislavski, Moscou

As políticas de Stalin para as artes precisaram de um modelo para o Realismo Socialista no teatro. Em virtude das jovens produções realistas que inauguraram o TAM, em 1898, e em virtude do seu renome internacional, assim como de sua idade venerável, Stanislávski, queira ou não queira, foi transformado no protótipo teatral de Stalin. Se ele próprio diferia da imagem criada, pouco importava. No decorrer de sua morte, o seu teatro tornou-se o modelo legal para todos os teatros na União Soviética e seu Sistema o currículo exclusivo para todos os institutos teatrais. Suas ideias mais experimentais foram abafadas, quaisquer técnicas espirituais e psicológicas que desafiassem o materialismo marxista também foram menosprezadas ou suprimidas, seu realismo juvenil e seu Método das Ações Físicas foram exaltados. Correspondências entre Stalin e Stanislávski, 
recentemente desenterradas nos arquivos do Teatro de Arte de Moscou, sugerem que, de fato, Stalin manipulou a imagem de Stanislávski no mundo, impondo-lhe um exílio quase completo, durante seus quatro últimos anos de vida. Nesse período, Stanislávski não saiu de casa, senão para fazer visitas curtas a clínicas de saúde, para exames médicos. Em um discurso feito para o quadragésimo aniversário do Teatro de Arte de Moscou, em 1938, o ano da morte de Stanislávski, o ator Leonid Leonidov, que interpretou Otelo na montagem de 1930, disse: "Stalin está em todos os nossos pensamentos, Stalin está em todos os nossos corações, Stalin está em todas as nossas canções, sua vida borbulha em nossos trabalhos e em nossas batalhas, Stalin, você é meu sol, obrigado!" (Smelianskii, 1989, p. 345; Smelianskii, 1988). Como aponta Anatoly Smelyansky, à época dramaturgo do TAM, tal declaração resume a absoluta rendição do Teatro de Arte de Moscou à Stalinização e seu consequente "suicídio artístico" (Smelianskii, 1989, p. 330).15

Os escritos de Stanislávski também foram propícios à causa. Em 1932, quando o governo decidiu criar uma escola-modelo de interpretação, adjunta ao Teatro de Arte de Moscou, An Actor Works on Himselfí [um ator trabalha sobre si mesmo] - sobre o qual Stanislávski, naquele momento, desprendia tantos esforços -, passou a ser menos um empreendimento pessoal. O governo viu o livro como a apresentação do currículo exemplar para a escola e, portanto, como seu principal manual didático. Nomeou-se uma comissão especificamente para examinar o livro e alinhá-lo com o materialismo dialético, que, como o próprio Stanislávski colocava, havia se tornado a filosofia "exigida a todos" sob o comunismo. ${ }^{17}$ Conforme expresso na Rússia Comunista, essa filosofia Marxista enxergava todos os aspectos do mundo como sendo motivados material, econômica e socialmente. Todas as outras formas de explicação foram pejorativamente rejeitadas como "idealistas".

15 (NA) Para uma abordagem mais completa dos últimos anos da carreira de Stanislávski, em inglês, ver Carnicke, 1992b, p. 152-165.

16 (NA) Essa tradução do título russo, Rabota aktera nad soboi, é mais literal do que a de uso corrente em inglês "An Actor Prepares" [Um ator prepara].

17 (NA) De uma carta a Elizabeth Reynolds Hapgood, de 7 de abril de 1932, Arquivo de Konstantin Stanislavskii (Dybovskii, 1992). 
Em 1930 e 1931, quando ela leu o manuscrito de An Actor Works on Himself, a velha amiga e editora de Stanislávski, Lyubov Gurevich, alertou-o para os "perigos" de seu trabalho que "a assustam". Ela conta-lhe que ele está vivendo "encarcerado no mundo de sua arte". Em uma carta de 1936 à sua tradutora em língua inglesa, Elizabeth Hapgood, Stanislávski revela como havia se tornado distante da sua sociedade, ao ficar pasmo com os jovens que agora estudavam no TAM. Ele via que, de fato, eles tinham crescido mediante circunstâncias sociais em que incorporaram, radicalmente, valores e atitudes diferentes em relação ao mundo e para uns com os outros. E dizia que eles eram "realmente novas pessoas". 18

Dois aspectos dos rascunhos de Stanislávski irritaram os detentores do poder. De um lado, muitos de seus exemplos e exercícios eram retornos a uma era passada de capitalismo e valores burgueses. E enquanto tal, foram recebidos como ofensivos pela juventude soviética. De outro lado, seu Sistema por si só baseado na premissa de que há uma ligação indissolúvel entre mente e corpo, espírito e carne - violou a filosofia exigida. O materialismo dialético russo rejeitou todas as escolas de psicologia em favor do behaviorismo, que busca causas físicas para fenômenos mentais. Somente a metade física da equação de Stanislávski foi, portanto, permitida, a outra metade foi considerada "idealista", uma crítica que perturbou Stanislávski durante os anos pós-revolucionários de sua carreira.

A primeira dessas críticas faz sentido quando vista à luz das realidades de um país destruído pela revolução e guerra civil, sofrendo uma ampla recessão econômica e privação material. Em um exercício de interpretação, Torstov, a persona fictícia de Stanislávski, solicita que sua aluna Maloletkova procure por um valioso broche. Ele conta-lhe que caso ela encontre-o, perdido em algum lugar do apartamento, ela pode certificar-se de que continuará os estudos na escola, pois o seu valor permitirá custear as aulas. Em um outro exercício, Stanislávski usa uma cena de uma peça na qual uma personagem herda uma fortuna, na realidade da

18 (NA) De uma carta de Gurevich a Stanislávski, 7 de abril de 1931, Arquivo de Konstantin Stanislavskii, no 8064 (Dybovskii, 1992); Gurevich a Stanislávski, abril de 1929, Arquivo de Konstantin Stanislavskii, no 8058 e de 17 de dezembro de 1930, no 8062 (Dybovskii, 1992). Stanislávski a Hapgood, outubro de 1936 (Dybovskii, 1992); ver também Smelianskii, 1990). 
Rússia Soviética, tais exemplos que falavam sobre ter joias e dinheiro eram ofensivos. No recorrente exercício - o étude $e^{19}$ do "dinheiro queimado" - um caixa que trouxe, à sua casa, uma grande quantidade de dinheiro do escritório para contá-lo, descobre que seu cunhado, deficiente mental, brincou de queimar todo o dinheiro. ${ }^{20} \mathrm{~A}$ ação física de manusear, contar e queimar dinheiro faz ressoar um tom particularmente perturbador, tendo em vista a pobreza daqueles tempos. Esses exemplos são marcantes sobretudo quando se leva em conta que o próprio Stanislávski sofreu as realidades econômicas de seu tempo. Ele havia perdido a empresa de fabricação de fios ${ }^{21}$ e a fortuna da família durante a revolução. Ele usou roupas surradas durante a turnê nos Estados Unidos e teve dificuldades para conseguir moeda forte suficiente para tratar o estado tuberculoso de seu filho. Sugerindo-the autocensura, sua amiga Gurevich o impeliu a procurar outros exemplos, no que Stanislávski respondeu que não conseguia pensar em nenhum outro e resistiu à pressão em tornar suas ideias contemporâneas. Ele quer escrever sobre verdades universais, ele diz, denominando seu sistema uma "psicotécnica de todos os tempos." 22 Seus exemplos originais permanecem no texto publicado.

O outro principal campo de censura, e o mais pernicioso, diz respeito à terminologia. Em correspondências de 1928 e 1929, Gurevich chama a atenção do seu amigo para termos como "memória afetiva" que não estão de acordo com as

19 (NT) No original em francês, étude, que significa "estudo", é um termo usado originalmente nas artes plásticas, que designa o método de trabalho em que se estuda (de maneira mais detalhada do que em um croqui ou esboço) a perspectiva, proporção, disposição etc. de partes ou da obra inteira, para que ela seja bem assimilada antes de pintada ou desenhada definitivamente. O termo foi incorporado pelas artes cênicas através de Stanislávski, que o desenvolveu enquanto método prático de improvisação de cenas ou trechos da peça, para que os atores estudem a dinâmica do texto, circunstâncias, conflitos, ações, situações etc., durante os ensaios.

20 (NA) Para mais exemplos como esse, ver (SS 1989, 11, p. 89 e 146).

21 (NT) Sergei Vladimirovich Alekseyev foi um grande empresário, um dos homens mais ricos da Rússia nos tempos do Czar, cuja fábrica produzia fios de ouro, matéria-prima usada na fabricação de uniformes e vestimentas, por exemplo, e, posteriormente, se especializando em fios elétricos. Seu filho, Constantin Stanislávski, assumiu a diretoria administrativa nos anos 1890, dividindo-se entre as funções de empresário, ator e diretor do TAM. Na fábrica ele organizou um grupo de teatro amador com os funcionários desde 1898 e, em 1904, foi construído um pequeno teatro no pátio da fábrica, funcionando até 1909. Em 1920, ao ser estatizada, a fábrica foi nomeada Elektroprovod (O cabo elétrico), até ser desligada em 1990. As dependências foram restauradas e reinauguradas, em 2007, como um complexo empresarial intitulado Fabrika Stanislavskogo (Fábrica Stanislávski), porém o antigo teatro da fábrica, desde 2005 sedia o Studiya Teatral'nogo Iskusstva (Estúdio de Arte Teatral), dirigido por Sergey Zhenovach.

22 (NA) Carta a Gurevich, 23 e 24 de dezembro de 1930 (SS, 1961, 8, p. 271). 
tendências predominantes da psicologia behaviorista soviética. Ela sugere repetidas vezes que ele procure por cientistas para obter uma melhor compreensão do pensamento soviético vigente. Em 1931, ela adverte que termos como "a vida do espírito humano", "alma” e o "se mágico" (que ela sugere que ele substitua por "se criativo") necessitam de "tesouras marxistas", porque eles invocam ideias imateriais as quais o materialismo dialético fortemente rejeita. Aliás, em 1936, o governo descreve tais termos ambíguos como "nebulosos" (tumannye), adicionando "intuição" e "subconsciente" à lista. ${ }^{23}$

Stanislávski pode ter concedido seu teatro a Stalin, porém ele defendeu seu livro, An Actor Works on Himself. Todos os conceitos atacados pelo materialismo dialético vão de encontro ao âmago do seu Sistema. Stanislávski os enxergava como componentes essenciais para a criatividade artística e defendeu todas as palavras suspeitas, como "alma" e "subconsciente", em uma carta ao Comitê Central do Partido Comunista (ver Benedetti, 1990a, p. 346-347). Para que se mantivessem os termos, o Partido, por sua vez, pediu que Stanislávski revelasse "de forma concreta" os conteúdos "realistas" nos textos (Ancharov, In: Dybovskii, 1992). Ambas as partes fizeram concessões, enquanto algumas passagens e frases desapareceram, tal como o "oceano do subconsciente"24, outras passagens foram ajustadas de formas que não excluíram suas ideias essenciais, mas eram mais palatáveis às autoridades. Um trecho que fala da "psicotécnica" em metáforas engenhosas, por exemplo, apareceu no capítulo 2 (SS, 1989, 2, p. 61). Da mesma maneira, sempre que Stanislávski menciona a mente e as emoções, ele reitera sua conexão com o corpo. Ao fazer tais concessões ao materialismo, Stanislávski preservou aspectos "idealistas" dentro dos textos, mesmo com os cortes e alterações feitos durante as primeiras tiragens, ele esquivou-se, com êxito, do censor. Esses livros russos ainda servem como uma das melhores chaves de leitura para suas verdadeiras questões sobre arte. Como o próprio Stanislávski

23 (NA) Gurevich a Stanislávski, abril de 1929 e 7 de abril de 1931, Arquivo de Konstantin Stanislavskii, no 8064 (Dybovskii, 1992); A.l. Ancharov do Comitê Central do Partido Comunista a Stanislávski, 22 de novembro de 1936, Arquivo de Konstantin Stanislavskii, no 12019 (Dybovskii, 1992).

24 (NA) De uma conversa pessoal com Benedetti a respeito de variantes do capítulo 16 de An Actor Works on Himself. 
havia contado a Gurevich, alterar palavras é uma coisa, mudar conceitos e ideias é outra (SS, 1961, 8, p. 286). Neste sentido, ele publicou um livro notável, dadas as condições da época.

Com o tanto de alma e subconsciente mantidos em seu livro, restou aos censores soviéticos fazer com que o conteúdo fosse mais aceitável ao Marxismo do que o texto em si. As interpretações soviéticas do Sistema enfatizaram seus aspectos físicos, privilegiando o Método das Ações Físicas diante de outras práticas experimentais para os atores. Tais interpretações asseguraram, posteriormente, que os livros de Stanislávski continuassem sendo tolerados. Por exemplo, o crítico Pavel Simonov ao, criteriosamente, fazer vista grossa aos aspectos mais espirituais do trabalho de Stanislávski, sujeita o Sistema a uma análise estritamente behaviorista (1962). Nesse empreendimento, Simonov conta, quase que exclusivamente, com apenas uma metade da compreensão psicológica de Stanislávski, mas ao fazer isso ele não toca na parte que é a menos aceitável. ${ }^{25}$ Tal dinâmica de interpretação, por si só, protegeu as próprias fontes, deixando elementos para leituras revisionistas intactos.

O retrato mítico de Stanislávski no Ocidente construiu-se de maneiras muito mais complexas e intrincadas do que na União Soviética. As turnês de 1923 e 1924 do Teatro de Arte de Moscou nos Estados Unidos, a transmissão indireta de informações sobre o Sistema aos atores estadunidenses e as publicações em língua inglesa de seus livros também contribuíram para essa retratação.

Stanislávski trouxe as mais antigas e realistas de suas montagens consigo, quando visitou os Estados Unidos. Ao passo que essas viagens certamente "nos encorajaram a rever nosso nível ordinário quanto aos valores dramáticos e teatrais", como estabelece a crítica R.A. Parker (Emeljanow, 1981, p. 242), elas também fixaram no nosso imaginário a imagem dele na sua fase prematura da história do Teatro de Arte de Moscou. Czar Feodor loannovich de Alexei Tolstói havia inaugurado o Teatro de Arte de Moscou, em 1898, e tinha 26 anos durante a primeira turnê. Todas as montagens de Tchekhov haviam sido encenadas até 1904,

25 (NA) O crítico estadunidense Burnet Hobgood, em seu artigo Stanislavski's books: an untold story (1986), alerta para esta peculiar dinâmica interpretativa soviética, contestando as edições russas. 
dois anos antes de Stanislávski ter chegado a sonhar com o Sistema. O repertório não refletiu os interesses vigentes do diretor. Claramente, o TAM havia escolhido esse repertório porque ele era menos controverso na Rússia soviética, onde guerras políticas contra as artes estavam começando. Contudo, profissionais do teatro estadunidenses, como Lee Strasberg, enxergaram virtude até na idade das montagens. "Nós somos sortudos", disse Strasberg aos membros do Actors Studio, "de ver não apenas montagens, mas obras de arte, (...) não apenas os sucessos daquele ano, eles trouxeram para nós os sucessos de sua carreira inteira. (...) Nós fomos privilegiados." (Strasberg, 1956-1969, 23 de abril de 1968). Essa escolha de repertório - em suma, as turnês em si - contribuiu para estabelecer Stanislávski nos Estados Unidos como um diretor e ator exclusivamente realista, par excellence.

Figura 2 - Stanislávski estava constantemente desenvolvendo suas teorias e, por isso, esteve sempre revisando seus cadernos. Ele também deixou inúmeros rascunhos inacabados para trás

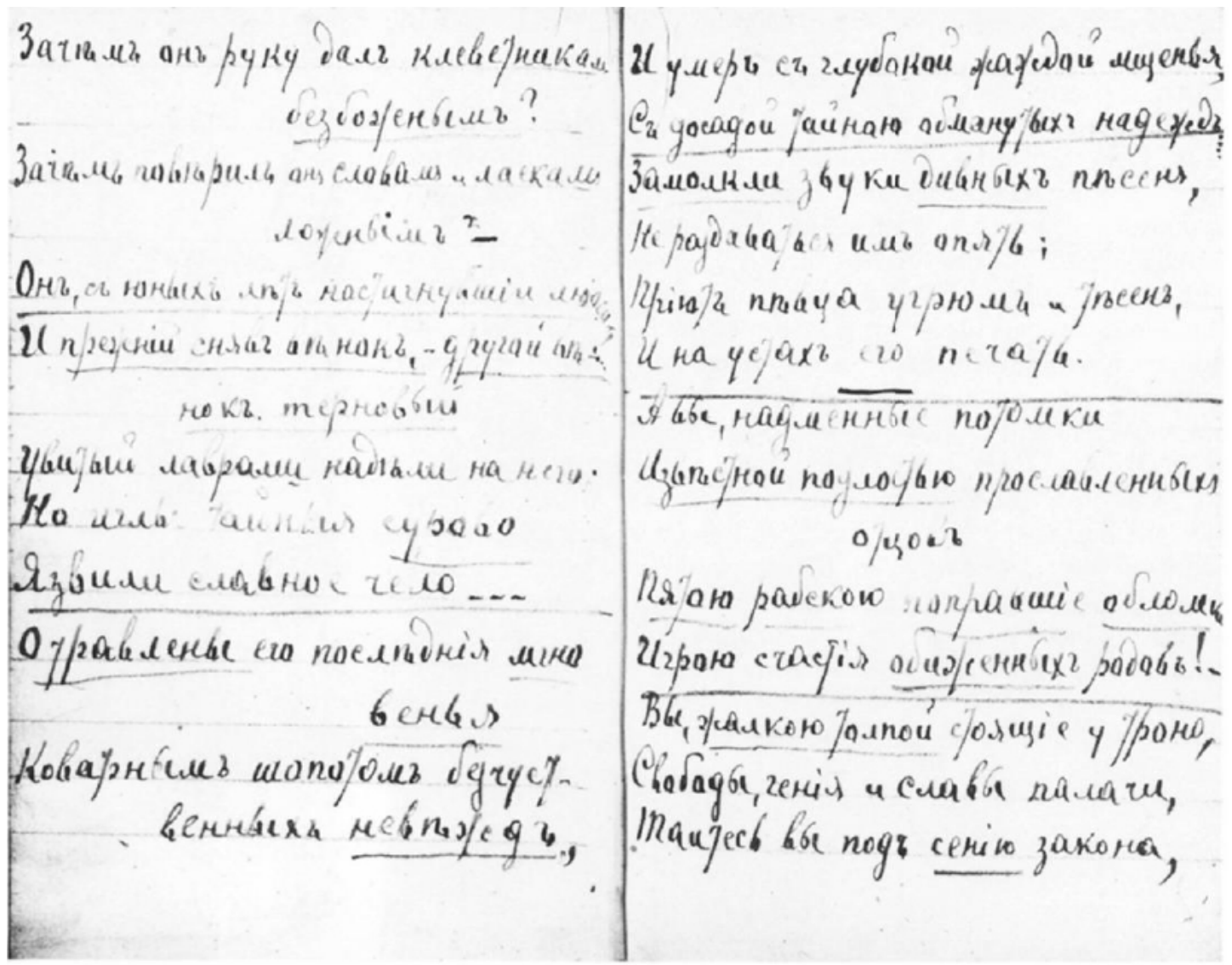

Imagem: Cortesia dos Arquivos de K. S. Stanislavski, Moscou 
Emergiu, nas salas de aula de professores emigrados, uma dinâmica criativa que, lentamente, mas certamente, converteu o Sistema no Método Americano. Ainda que o interesse por Stanislávski tenha crescido nas décadas de 1920 e 1930, nos Estados Unidos, pouca informação escrita podia ser encontrada. Os atores até podiam assistir aos resultados dos ensaios de Stanislávski no palco, mas pouco podiam inferir do processo criativo das montagens em si, informação escrita era escarça. Eles não possuíam texto melhor do que My Life in Art (1924) ${ }^{26}$, um livro de memórias escrito, em parte, para estimular a publicidade em torno das viagens de Stanislávski aos Estados Unidos. An Actor Prepares apareceu em 1936, cinco anos completos desde a fundação do Group Theatre em Nova York, que já havia adaptado diversos métodos de Stanislávski para uso próprio. Do Grupo, apenas Stella Adler estudou com Stanislávski diretamente e, ainda, por um curto intervalo de tempo. Sendo assim, aqueles que procuraram estudar o Sistema se viraram aos professores emigrados, que transmitiam suas experiências do Sistema por meio de aulas, ao invés de textos.

O principal dentre eles era Richard Boleslavsky, que literalmente se definiu a si mesmo como o primeiro "porta-voz" de Stanislávski, em inglês. Boleslavsky, um antigo membro do Teatro de Arte de Moscou, havia emigrado em 1919 e se encontrou com Stanislávski, em Nova York, para auxiliar com o trabalho das turnês. Com a autorização de Stanislávski, ele proferiu uma série de palestras sobre interpretação, concomitantes com apresentações da companhia. Embora tenha escrito o primeiro artigo sobre o Sistema em língua inglesa (1923), tinha um total de três páginas. Seu livro posterior, Acting: The First Six Lessons (1933), baseado, assim como An Actor Prepares, nessas palestras iniciais, data depois da fundação do Group Theatre. O papel da oralidade na transmissão das ideias de Stanislávski não deve ser ignorado, aulas de interpretação estiveram presentes na criação do nosso senso comum sobre o Sistema.

Esse modo de transmissão, entretanto, envolve inúmeros obstáculos. Professores emigrados eram, de fato, a melhor fonte de informação, mas eram

26 (NT) Edição traduzida por J.J. Robbins e publicada pela editora Little, Brown and Company (Boston). Até o presente momento, a única versão deste livro, em português, apareceu, em 1989, como Minha Vida na Arte, foi traduzida do russo por Paulo Bezerra e publicada pela editora Civilização Brasileira. 
fontes imperfeitas. Eles falavam em uma língua estrangeira, às vezes tendo dificuldades para explicar conceitos que thes eram claros em russo, mas transmitidos de maneira um pouquinho diferente no novo meio cultural. Aliás, para o polaco Boleslavsky, o inglês era sua terceira língua. Basicamente, os "pedaços" [bits] da peça, encadeados uns nos outros como "contas" [beads] de um colar, tornaram-se as "unidades" [beats] da cena e memória "afetiva" virou "efetiva", ao ser pronunciada com o sotaque russo. ${ }^{27} \mathrm{Em}$ um nível mais sutil, o entendimento russo de "memória emocional" ficou confuso frente à psicologia Freudiana, popular nos Estados Unidos, mas não adotada na Rússia. É claro, a própria essência das aulas de interpretação - que necessariamente permeiam o Sistema através da criatividade individual dos professores e, igualmente, dos alunos, assim como numa brincadeira de telefone sem fio - , transforma, lenta, mas definitivamente, o princípio das ideias. Por fim, a maioria dos professores emigrados, como Boleslavsky, havia trabalhado com o Sistema em sua fase inicial, durante o primeiro Estúdio do Teatro de Arte de Moscou, fundado em 1911. Ali foram realizados os primeiros experimentos do Sistema. Logo, esses professores, assim como as turnês em si, apresentaram aos atores estadunidenses o pensamento mais antigo de Stanislávski (ver Carnicke, 1992a). Em suma, a sala de aula exerceu sua própria pressão na criação de um mito.

Ambas as forças - as turnês e os professores — operaram muito sutilmente, para que se possa fazer, neste artigo, mais do que apontar suas dinâmicas (ver

27 (NT) No original: On the simplest level, Stanislavsky's 'bits' of the play, strung together like the 'beads' of a necklace, became the 'beats' of the scene, and 'affective' memory became 'effective' when pronounced in a Russian accent. A autora usa palavras foneticamente parecidas, próprias do inglês, entre elas bit ("pedaço", "bocado"), bead ("conta", "missanga") e beat ("batida", "tempo" e "ritmo"), para propor as possíveis ambiguidades linguísticas ocorridas na transmissão de um idioma estrangeiro, como a específica confusão mencionada na pronúncia das palavras affective (afetivo) e effective (efetivo), por Boleslavsky. Em outra obra da autora, esse problema linguístico é, conceitualmente, mais bem elucidado na entrada para a palavra bit, no glossário do livro, a tradução é minha:

Bit (Kusok): O segmento ou 'unidade' (tradução de Hapgood) analíticos em que o ator divide cada cena de uma peça. Um novo "bit" [unidade de ação] começa sempre que uma ação ou contra-ação muda, seja na maneira de sua execução, seja na estratégia construída pela interação mútua dos parceiros de cena. Nos Estados Unidos, esse termo foi trocado por 'beats', que pode ter sido derivado de 'bits' [unidades] da peça, encadeados uns nos outros como 'contas' [beads] de um colar, ao serem pronunciados com o sotaque russo de professores emigrados. Na prática: durante a Cognição Afetiva, os atores definem suas mudanças estratégicas na ação ("bits"), por meio de discussões e estudo individual em casa. Durante a Análise-Ação, os atores descobrem tais mudanças conforme elas acontecem durante as improvisações [études]. (Carnicke, 2009, p. 214). 
Carnicke, 2009). Ainda assim, mesmo esse breve esboço já estabelece o cenário para o crucial enredo sobre a história da publicação de Stanislávski no Ocidente, que corrobora drasticamente com a necessidade de novas e mais fidedignas fontes primárias em inglês. Dentro desse contexto de informação oral e indireta, os livros de Stanislávski pareciam preencher uma demanda específica por fontes escritas, contudo, a publicação em si também teve seu papel na criação do mito.

Stanislávski escolheu publicar seus dois primeiros livros em inglês, um idioma que ele não falava nem lia, antes de publicá-lo em russo. Ele estava com uma necessidade extrema por moeda forte. Sua riqueza pessoal foi completamente perdida com a estatização de todas as propriedades privadas após a revolução e seu filho estava gravemente doente com tuberculose. Embora o Teatro de Arte de Moscou houvesse encontrado uma de suas plateias mais entusiastas nos Estados Unidos, Stanislávski havia atingido o mais profundo nível de desespero. "Estou perdendo o que resta da minha saúde. Meu ânimo está baixo, estou depressivo, quase desencorajei-me e, às vezes, eu penso em desistir de tudo" (Benedetti, 1990a, p. 278). Essa desesperança também se estendeu ao futuro do seu teatro, como ele escreveu, de Nova York, a seu codiretor, Vladimir NemiróvitchDántchenko, em 1923:

Devemos nos acostumar à ideia de que não há mais Teatro de Arte. [...]. Todos esses anos eu fiquei me enganando em esperanças e resguardando as sobras decadentes. Durante nossas viagens, isso ficou cada vez mais claro, mais evidente, definitivamente. Ninguém possui uma reflexão, ideia, nenhuma grande meta, e sem isso, um empreendimento baseado em ideias não pode sobreviver. (SS, 1961, 7, p. 41).

Os Estados Unidos pareciam oferecer a única saída para o desespero de Stanislávski. As turnês, sem sombra de dúvidas, representaram uma estratégia de sobrevivência financeira. Stanislávski acionou metade da companhia do TAM para a viagem num esforço de salvar o teatro da ruína financeira pós-Revolução. Como ele escreveu numa correspondência a Nemiróvitch-Dántchenko, de 12 de fevereiro de 1924, “A América é a única audiência, a única fonte de dinheiro para subsídio, 
com a qual podemos contar" (SS, 1961, 7, p. 84). Apesar do entusiasmo das plateias, lucros infelizmente continuaram a escapar ao teatro.

Da mesma forma, publicar no Ocidente deu a Stanislávski uma estratégia financeira. A lei de direitos autorais dos Estados Unidos, junto com as outras leis sobre direitos de autor internacionais, asseguravam que ele ganhasse dinheiro rápido com todas as traduções de seus livros e que os ganhos futuros continuassem a entrar para sua família. A lei soviética não podia garantir nem os direitos de autoria da obra nem royalties, à época. Conforme ele explicou ao seu codiretor:

Não se pode viver de teatro, eu nunca devo me esquecer disso, jamais. Precisei buscar outras formas, escrevendo um livro (por exemplo). Você provavelmente supõe que estou fazendo isso por prazer, mas você sabe minha relação com canetas e papel. Estou fazendo isso apenas pela mais dura e extrema necessidade. (SS, 1961, 8, p. 82).

Independentemente de quão inteligente, do ponto de vista financeiro e legal, a decisão de Stanislávski teve um resultado irônico: a lei de direitos autorais protegeu as versões dos livros, que o próprio Stanislávski considerava problemáticos. Little, Brown and Company recusou um primeiro manuscrito técnico (atualmente Localizado na Universidade da Califórnia, em Berkeley) e solicitou que ele compusesse livros de memórias comercialmente mais viáveis. Então ele escreveu Minha Vida na Arte apressadamente, para que pudesse ser publicado ainda em 1924 durante a segunda turnê nos Estados Unidos. Como ele mesmo disse, ele trabalhou "como um condenado, com apenas poucos dias sobrando para viver" (SS, 1961, 8, p. 87). ${ }^{28}$ Ele estava infeliz com os resultados e, quando retornou a Moscou, revisou completamente seus livros; a revisão russa que ele considerava definitiva ainda não havia sido traduzida em inglês.

O manuscrito de An Actor Prepares foi, igualmente, considerado não comercial. Inicialmente, a imprensa da Universidade de Yale o recusou, Stanislávski havia perdido inúmeros prazos e o livro estava crescendo a um tamanho excessivo.

28 (NA) Em uma correspondência de Stanislávski a Z.S. Sokolova e V.S. Alekseev, abril de 1924. Para uma completa e excelente descrição sobre a criação de My Life in Art, ver (Senelick, 1981, p. 201-211). 
Theatre Arts Books concordou em publicá-lo, mas apenas com a condição de que a tradutora Elizabeth Reynolds Hapgood fizesse significantes cortes e modificasse as referências russas, tidas como obscuras demais para seu público leitor. A editora Edith Isaacs explicou à Hapgood que o livro, para ela, parecia "praticamente irrelevante para ser publicado nesse formato", pois não seria assimilável a leitores "anglo-saxônicos" (Hapgood, 1986, p. 159). A nível mais superficial, as versões subsequentes, altamente reduzidas em inglês (metade do tamanho das russas), prejudicaram muito a lógica cuidadosa de Stanislávski e as descrições minuciosas do processo experimental de interpretação, sumindo com seu estilo Socrático e muito da sua perspicácia durante o processo. ${ }^{29}$

Ao passo que Stanislávski, em 1924, testava o terreno com a publicação ocidental de Minha Vida na Arte, ele formalizaria acordos para todos seus próximos Livros, em 1930. Na França, recuperando-se de um ataque cardíaco, ele assinou um contrato jurídico com Hapgood, dando-lhe direitos de publicação e tradução de todos os seus livros, atuais e posteriores, em todas as línguas, inclusive russo, (ele também incluiu direitos de gravação e de imagem). ${ }^{30}$ Eles se encontraram pela primeira vez e ficaram amigos em 1924, ela havia trabalhado como intérprete dele e de sua companhia quando eles foram apresentados a Calvin Coolidge, na Casa Branca. Esse contrato extraordinário foi concebido para garantir proteção sobre os direitos autorais estadunidense e internacional a todos os seus textos.

Após o acordo de 1930 e até sua morte em 1974, Hapgood operou como uma "procuradora” do patrimônio de Stanislávski, controlando todos os seus livros no Ocidente. Na sua função como representante de Stanislávski, ela negociou com tradutores e editores ocidentais, protegeu seus interesses legais e financeiros e difundiu sua relevância ao redor dos Estados Unidos e em outros países. Sem seus esforços, os escritos de Stanislávski certamente teriam levado muito mais tempo

\footnotetext{
29 (NA) Para um tratamento mais completo e uma análise profunda de como o termo "objetivo" foi distorcido pelas traduções, ver (Carnicke, 1984).

${ }^{30}$ (NA) Uma cópia desse acordo está no Theatre Arts Books Archives, nos escritórios da Routledge, em Nova York.
} 
para serem conhecidos fora da Rússia. Depois da morte dela, o patrimônio de Hapgood assumiu o controle como "procurador" de Stanislávski.

Figura 3 - As "notas de processo para o ator" de Stanislávski aqui incluem desenhos. Um extenso escritor, ele contou com editores para ajudá-lo a cumprir prazos

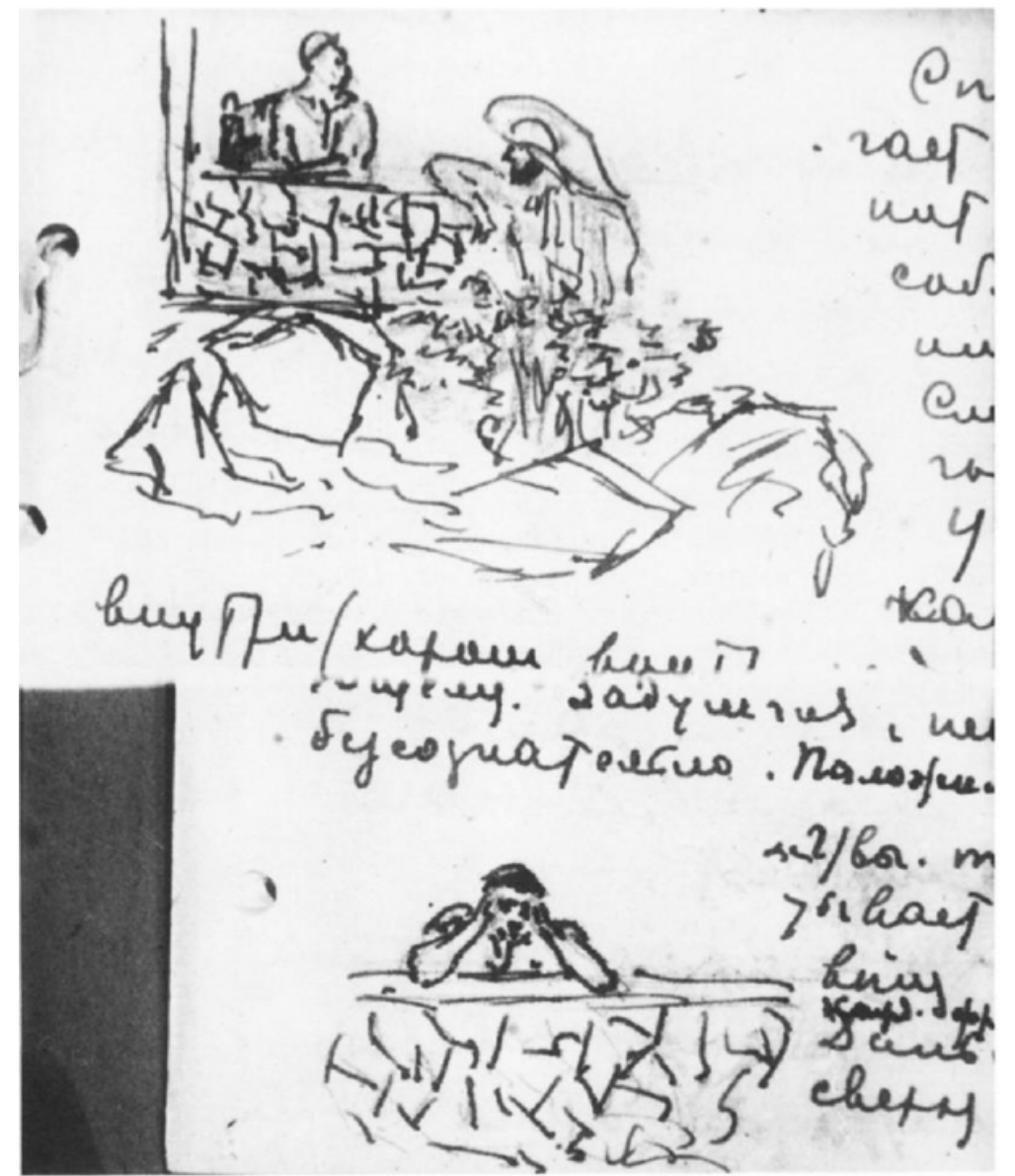

Imagem: Cortesia dos Arquivos de K. S. Stanislavski, Moscou

Embora protegendo os interesses financeiros de Stanislávski, esse contrato também consagrou as versões reduzidas e problemáticas de seus livros em inglês como os únicos textos oficiais. Uma vez publicadas, as traduções inglesas tornaram-se as versões oficiais e inéditas, protegidas pela lei de direitos autorais. Quaisquer traduções concorrentes dos livros russos ameaçariam tal copyright. Consequentemente, Hapgood defendeu veementemente suas versões dos livros publicadas, embora ela mesma tenha reclamado contra alguns cortes solicitados 
pela Theatre Arts Books. ${ }^{31}$ Quando contratos foram feitos para se traduzir Stanislávski em outros idiomas, Hapgood naturalmente insistiu que todas as traduções seguissem as suas versões e não as últimas edições russas. Seu direito de fazer isso foi preservado pelos tribunais italianos, quando o Theatre Arts Books contestou uma tradução de 1956, feita diretamente do russo (Bari: Editori Laterza). A edição em disputa foi retirada de produção e uma nova tradução italiana foi feita a partir da versão inglesa. Como provam suas correspondências, ela também reviu, regularmente, as traduções de terminologias em outras línguas e, às vezes, até insistiu sobre a escolha de tradução, como ela fez com a edição francesa de $A n$ Actor Prepares (Paris: Olivier Perrin, n.d.) ${ }^{32}$

As únicas traduções que escaparam do seu controle foram uma coleção em espanhol publicada na Argentina e uma edição da Alemanha Oriental (ver também Benedetti, 1990b, p. 266-278).

Como estipulado pelo seu contrato com Stanislávski, o controle dela estendeu-se para além dos livros que ela própria traduzira, incluindo todos os escritos dele. De modo que, em 1948, ela adquiriu os direitos sobre a tradução, de 1924, de J.J. Robbins de My Life in Art. Ela também negociou autorizações para a publicação de outros materiais e citações em estudos acadêmicos, os quais não foi ela em si quem traduziu.

Em suma, como os livros em inglês eram, legalmente falando, as fontes em idioma oficial para a obra escrita de Stanislávski, Hapgood e sua editora, Theatre Arts Books, resguardaram-se das traduções rivais, defendendo, com êxito, em tribunais internacionais, o contrato firmado em 1930. Além disso, uma vez que os direitos autorais garantiram que todas as traduções de Stanislávski fossem feitas a partir do inglês e não do russo, a pressão comercial que modificou a obra de Stanislávski nos Estados Unidos difundiu-se para a maior parte do Ocidente e até

\footnotetext{
31 (NA) Na realidade, para proteger o acordo com Stanislávski a longo prazo, ela e seu marido registraram-se junto à Biblioteca do Congresso Washington, EUA] como coautores de An Actor Prepares, eles haviam passado quase um ano com Stanislávski na Europa auxiliando-o com suas aparentemente infinitas revisões do livro. Para mais detalhes, ver (Hobgood, 1986).

32 (NA) Correspondência obtida pelo Elizabeth Hapgood Archive, Performing Arts Research Collection, New York: New York Public Library.
} 
o Japão. A história dessa publicação e tradução indica que as escolhas de Hapgood em terminologia e estilo, somadas a decisões editoriais da Theatre Arts Books, prevaleceram como a forma dominante das ideias de Stanislávski fora da Rússia. Como o acadêmico estadunidense Burnet Hobgood tão sucintamente apontou, nós padecíamos de uma "cortina inglesa" (1973, p. 158).

Que diferenças existem entre as edições, publicadas em inglês e russo, da obra de Stanislávski não é nenhuma novidade. Não apenas os livros são significantemente mais curtos em inglês, mas também as terminologias são traduzidas inconstantemente e, às vezes, de forma incorreta. Joshua Logan, um dos poucos diretores estadunidenses que viajou até a União Soviética para estudar diretamente os métodos de Stanislávski, testemunhou desavisadamente essas diferenças, quando escreveu: "os livros que Stanislávski escreveu são difíceis de se compreender nas traduções inglesas. Seus escritos não são nem de longe tão vívidos quanto seu discurso" (Senelick, 1981, p. 209). De fato, Stanislávski, enquanto escritor, é muito mais dinâmico do que sua aparência em língua inglesa.

Já nos idos de 1954, Henry Schnitzler, professor adjunto de teatro na Universidade da Califórnia Los Angeles [UCLA], analisou as discrepâncias entre o Stanislávski inglês e o russo, depois de ler uma tradução alternativa, mas não publicada, da versão em língua inglesa. Embora não lesse russo, ele foi atrás da tradução não-autorizada em alemão, para confirmar sua primeira impressão de que An Actor Prepares não era o Sistema completo e de que Building a Character revelava "uma surpreendente falta de cuidado editorial" (1954, p. 13). A editora Theatre Arts Books recebeu seu artigo como um ataque. Hapgood pediu que sua amiga, Varvara Bulgakova, escrevesse uma resposta. Bulgakova havia sido atriz no Teatro de Arte de Moscou, ela viajou com o teatro aos Estados Unidos e permaneceu por lá, depois que Stanislávski regressou. Ela assegurou que a representação do Sistema de Stanislávski por parte de Hapgood era precisa. Além da resposta dela, a editora providenciou uma comparação das versões russas e 
inglesas feitas. Tal comparação resultou em uma notória declaração de que nada substancial havia sido eliminado no processo editorial. ${ }^{33}$

Contudo, conversas sobre tais discrepâncias percorreram a comunidade acadêmica até chegarem ao teatro profissional mundial. Em 1969, durante uma sessão gravada no Actors Studio, em Nova York, Lee Strasberg disse que "os livros [de Stanislávski] dão uma impressão errada, os livros são traduzidos de maneira parcialmente incorreta em inglês, [...] as edições estadunidenses são versões editadas, editadas não por Stanislávski, mas pela tradutora, que se fez, digamos assim, responsável pela apresentação do material de Stanislávski sob uma forma que ela considera ser adequada" (Strasberg, 1956-1969, 15 de janeiro de 1961). Strasberg, assim como Schnitzler, havia lido a versão não-autorizada em alemão, em uma carta ao editor da Tulane Drama Review, ele escreveu: "Àqueles inaptos para consultar [os artigos de Stanislávski] em russo [...], discussões valiosas do sistema de Stanislavski $[\mathrm{sic}]^{34}$ podem ser consultadas em traduções alemãs. Estou surpreso que tão pouca atenção foi dada a elas, pelos estudiosos estadunidenses. (Strasberg, 1966, p. 239). Aliás, ele listou os livros alemães na bibliografia de seu artigo "Acting" da Encyclopaedia Britannica, comentando que eles "são essenciais para um estudo sério" (Strasberg, 1957, p. 63).

Eric Bentley também consultou as traduções alemãs: “Alguns de nós que não são capazes de ler Stanislávski em russo, já leram bastante dele nas admiravelmente completas traduções alemãs." Ele observou que todas as referências a Théodule Ribot, o psicólogo do qual Stanislávski tomou emprestado o termo "memória emocional", foram excluídas das edições em inglês. "Mistério é criado", ele queixa-se, "apenas quando um tradutor decide omitir tanta coisa que é importante (...)." Ele sentiu que tais cortes, sobretudo à luz da importância da

\footnotetext{
33 (NA) Por meio de cartas de Robert MacGregor, 29 de junho de 1954 e 2 de agosto de 1954, The Elizabeth Reynolds Archive, Performing Arts Research Collection, New York: New York Public Library, ver também (MacGregor, 1966, p. 181).

34 (NT) A autora aponta a grafia incorreta, feita por Strasberg, em que "Stanislavsk" deveria encerrar-se com "y", ao invés de "i", em inglês. Resolvi usar a grafia ipsis litteris do trecho citado, não empregando o acento agudo no segundo "a" de "Stanislávski", como convencionado nesta tradução.
} 
memória emocional no Método Americano, foram nocivos a estudiosos de teatro (Bentley, 1962, p. 128).

Uma última palavra de atenção deve ser adicionada a respeito das variações que existem entre as edições estadunidenses e russas dos manuais de interpretação. Como analisado anteriormente, todos os textos de Stanislávski são trabalhos em andamento, suas constantes revisões produziram muitos textos diferentes. As páginas que Hapgood traduziu, editou e reduziu não eram exatamente os mesmos textos que foram adaptados aos requisitos soviéticos. No que diz respeito a An Actor Prepares, Jean Benedetti corretamente observa que nós estamos "diante de duas versões do mesmo trabalho, baseadas em dois cenários de decisões editoriais distintos, ambos os quais parecem, numa ocasião ou noutra, ter tido a aprovação de Stanislavski [sic]" (1982, p. 79). Sem acesso a essas variantes, questões centrais permanecem sem resposta: Quais textos datilografados Hapgood realmente leu? Stanislávski fez alterações especificamente direcionadas ao público estrangeiro, como ele fez para seu público russo quando revisou Minha Vida na Arte? Há, de fato, versões que representam um "Stanislávski puro", intocado por outras mãos?

Ao menos para um volume, perguntas como essas podem agora ser respondidas. Em 1935, Stanislávski enviou a Hapgood uma versão de seu magnum opus ${ }^{35}$, An Actor Works on Himself, Part 1. Ele identificou essa versão como a "definitiva para a América" e rubricou todas as páginas. Hapgood traduziu e editou essa versão, que ficou conhecida como An Actor Prepares. Este original datilografado foi liberado pelos patrimônios de Hapgood e Stanislávski e, agora, variantes entre eles podem ser comparadas (Carnicke, 2009). A história dos livros de Stanislávski, tanto na URSS quanto nos EUA, cria o cenário para as novas publicações, que agora estão emergindo.

A editora russa, Iskusstvo, está reeditando todos os materiais anteriormente impressos na antiga edição soviética, de 1954 a 1961, em oito volumes, expandida a partir de novas pesquisas nos Arquivos do Teatro de Arte Moscou. Assim, Minha

35 (NT) Do latim, obra-prima. 
Vida na Arte e os manuais de interpretação agora aparecem em versões completas com notas copiosas contendo variantes dos rascunhos. O mais radical é a inclusão de materiais recém encontrados, publicados pela primeira vez. Por exemplo, os "Cadernos de Notas do Artista" que Stanislávski compôs durante muitas décadas, aparecem como ele próprio os organizou - montagens compostas de pensamentos aleatórios sobre atuação, ideias de direção e partituras ${ }^{36}$ para peças, resenhas críticas sobre o que ele via nos palcos e lia, correspondências de pessoas famosas, que ele cuidadosamente preservava e colava nas páginas dos seus cadernos. E como eram privados, eles escaparam da censura que seus livros formais enfrentaram. Em uma edição anterior, apenas trechos desses escritos pessoais foram selecionados e simplesmente reunidos pelos editores para publicação, tumultuando o fluxo dos pensamentos de Stanislávski (Stanislavskii, 1986). Outros volumes incluirão correspondências com figuras importantes na arte e política do século XX e com aqueles que Stanislávski era mais próximo. Cartas a Stalin e outros membros do governo revelam fatos pouco conhecidos durante a idade mais avançada de Stanislávski e sobre a história do Teatro de Arte de Moscou, na década de 1930; cartas a seu codiretor Nemiróvitch-Dántchenko mostram uma relação de longa data, mas de ambíguos amor e ódio; seus escritos a Hapgood e cartas à sua esposa, só recentemente liberadas pela sua família, demonstram preocupações pessoais. Como escreve Smelyansky: "Desta vez, nós publicaremos Stanislávski com ele é em sua totalidade, com todas as contradições na mente que distinguem um artista vivo dos charlatões, que geralmente advêm da imagem de uma grande pessoa. O leitor terá a oportunidade de embarcar no grande laboratório de suas ideias e entender o percurso que suas experimentações tomaram. E, certamente, isso é o mais importante agora!" (Smelianskii, 1992).

Anatoly Smelyansky escreveu que o objetivo da nova edição russa deve ser "descobrir o artista de uma nova maneira. Stanislávski precisa disso, talvez mais

\footnotetext{
${ }^{36}$ (NT) No original plans, "plantas", "planos", diz respeito aos "mapas" ou "desenhos" de cena que indicam as movimentações das personagens numa peça, sendo, portanto, um registro valioso para imaginar e compreender a encenação de algumas montagens históricas do TAM. Optei pelo uso do termo "partitura", usado por estudiosos e adotado em trabalhos relevantes sobre o tema como a dissertação de mestrado de Tieza Tissi, publicada sob o título "As Três Irmãs, de Tchékhov, por Stanislávski” (2018), pela editora Perspectiva.
} 
do que os outros, ele penou muito com a mitologia de Stalin, que tentou adequar suas ideias. E ele também sofreu nesses novos tempos, em que novas mitologias são proclamadas, no lugar de outras. (Smelianskii, 1992). O Ocidente, também, já sofre com mitologias similares criadas sobre Stanislávski, desde a década de 1930, e nós, assim como os russos, precisamos repensar o seu legado, de uma nova maneira.

\section{Referências}

BENEDETTI, Jean. Stanislavski: An Introduction. New York: Theatre Arts Books, 1982. BENEDETTI, Jean. Stanislavski: A Biography. New York: Routledge, 1990a.

BENEDETTI, Jean. A history of Stanislavski in translation. New Theatre Quarterly, n. 23, p. 266-278, ago. 1990b.

BENTLEY, Eric. Who was Ribot? Or did Stanislavsky know any psychology? Tulane Drama Review, v. 7, n. 2 (TI9), p. 127-129, 1962.

BOLESLAVSKY, Richard. Stanislavsky: The man and his methods. Theatre Arts Magazine, n. 37, p. 27, 74, 80, abr. 1923.

BOLESLAVSKY, Richard. Acting: The First Six Lessons. New York: Theatre Arts Books, 1933.

CARNICKE, Sharon M. An Actor Prepares/Rabota aktera nad soboi: A comparison of the English with the Russian Stanislavsky. Theatre Journal, v. 36, n. 4, p. 481494, dez. 1984.

CARNICKE, Sharon M. Boleslavsky in America. In: SENELICK, Laurence (org.). Wandering Stars: Russian Emigré Theatre (1905-1940), Iowa City: University of Iowa Press. 1992a.

CARNICKE, Sharon M. Stalinslavsky: Stanislavsky's Last Years. Theatre Three, n. 10/11, p. 152- 165. 1992b.

CARNICKE, Sharon M. Stanislavsky in Focus: an acting master for the twenty-first century. 2. ed. New York: Routledge, 2009.

DERMAN, A. Literaturnaya gazeta, 15, VIII, n. 45, p. 5. 1938. 
DIXON, Leslie. Outrageous Fortune. Direção: Arthur Hiller. Touchstone Pictures. 1987.

DYBOVSKII, Vladimir. V Plenu predlagaemyx obstoiatel'stv. Minuvshee, 10. Paris: Atheneum. 1992.

EMELJANOW, Victor. (org.) Chekhov: The Critical Heritage. Boston: Routledge and Kegan Paul. 1981.

GELBARD, Larry; SCHISGAL, Murray. Tootsie. Direção: Sydney Pollack. Columbia Pictures. 1982

GRIGOR'EV, A. Trud, 10, VIII, n. 183, p. 3-4. 1938.

GUS, M. Sovetskoe iskusstvo, 6, n. 412, p. 3-4. 1938.

HOBGOOD, Burnet. Central conceptions in Stanislavski's system. Educational Theatre Journal, v. 25, n. 2, p. 147-159. 1973.

HOBGOOD, Burnet. Stanislavski's books: an untold story. Theatre Survey, v. 27, n. 1 e 2, p. 155-165. 1986.

HOOVER, Marjorie. Review of Meyerhold at Work. SCHMIDT, Paul (org.). The Slavic Review, v. 41, n. 1, p. 194, mar./maio. 1982.

KHAILOV, L. Sovetskaya Belorussiya. 9, VIII, n. 138, p. 2. 1938.

MACGREGOR, Robert. Further entries for a chronology. In: MUNK, Erica (org.). Stanislavsky and America. New York: Hill and Wang, 1966. p. 178-181.

SCHNITZLER, Henry. Truth and consequences of Stanislavsky misinterpreted. Quarterly Journal of Speech, v. 40, n. 2, p. 3-15, abr. 1954.

SENELICK, Laurence. Stanislavsky's double life in art. Theatre Survey, v. 22, n. 2, p. 201-211. 1981.

SIMONOV, Pavel Vasilievich. Metod K. S. Stanislavskogo i fiziologiia emocii. Moscow: Akademiia nauk. 1962.

SMELIANSKII, Anatolii Mironovich. Stanislavski et le Stalinisme. Artigo apresentado no colóquio sobre Stanislávski: Le Siècle Stanislavski, Centre Georges Pompidou, Paris, 2-6 nov. 1988.

SMELIANSKII, Anatolii Mironovich. Mikhail Bulgakov v Khudozhestvennom teatre. Moscow: Iskusstvo. 1989. 
SMELIANSKII, Anatolii Mironovich. Artigo não publicado, apresentado em Stanislavsky in a Changing World, International Center for Stanislavsky Studies Moscow. 1990.

STANISLAVSKII, K.S. My Life in Art. Trad. J.J. Robbins. Boston: Little, Brown, \& Co, 1924.

STANISLAVSKII, K.S. Sobranie sochinenii. Moscow: Iskusstvo, 1954-1961. 8 v.

STANISLAVSKII, K.S. Iz zapisnyx knizhek. Moscow: VTO. 1986. v. 1 e 2.

STRASBERG, Lee. The Actors Studio. Gravação de áudio, n. 339A. Madison: Wisconsin Center for Film and Theatre Research at the State Historical Society of Wisconsin. 1956-1969.

STRASBERG, Lee. Acting. Encyclopaedia Britannica, v. 1, p. 58-64. 1957.

STRASBERG, Lee. Letter to the editor. Tulane Drama Review, v. 12, n. 1 (T33), p. 234239. 1966.

YURA, G.P. Sovetskoe iskusstva, 6, n. 412, p. 3. 1938.

Recebido em: 12/01/2021

Aprovado em: 13/01/2021 